\title{
AC 2011-1507: THE HUMBLE HISTORY OF THE "BULLET"
}

\section{Kathryn A. Neeley, University of Virginia}

Kathryn A. Neeley is an associate professor in the Department of Science, Technology, and Society in the School of Engineering and Applied Science at the University of Virginia. Her research uses cultural history of science and technology to gain a critical perspective on contemporary communication practices.

\section{Michael Alley, Pennsylvania State University}

Michael Alley is an associate professor of engineering communication at Pennsylvania State University. $\mathrm{He}$ is the author of The Craft of Scientific Presentations (Springer, 2003) and performs research on effectiveness of different slide structures at communicating engineering and science.

\section{Dr. Kathryn A. Neeley, University of Virginia}




\title{
The Humble History of the "Bullet"
}

\author{
"Engineers. . .are not superhuman. . . . That they make mistakes is forgivable; \\ that they catch them is imperative. Thus it is the essence of modern engineering. . . \\ to have one's work checked and to be able to check the work of others. \\ In order for this to be done, the work must. . .be an understandable piece of \\ technical communication."
}

- Henry Petroski, To Engineer Is Human, 2005 ${ }^{\mathrm{i}}$

\section{Introduction}

Bullet lists are a common - many would say "ubiquitous"-feature of written and oral communication in business, government, academia, the military, and civil society. They are particularly important in technical communication, as illustrated by a 2009 study that revealed that bullets appear on more than two-thirds of the slides in engineering presentations, including presentations at engineering education conferences. ${ }^{\text {ii }}$ Their pervasiveness suggests that they serve important functions. The plentiful and vociferous critiques of bullet lists as commonly used in PowerPoint presentations reflect a growing sense that bullet lists used injudiciously are a seriously flawed form of communication. The quote from Henry Petroski with which this paper begins highlights the ethical dimensions of flawed communication: if bullet lists make it more difficult to discern faulty reasoning or ill-founded conclusions, they make it harder for engineers to meet their professional obligation to protect the welfare and safety of the public and the interests of their employers and clients.

This inquiry into the history of bullets is designed to help engineers and technical communicators understand how we arrived at our current situation so that we might improve it. Specifically, this history illuminates the range of technical, organizational, and cultural factors that led to the emergence, proliferation, and critique of bullet lists. The arc of that history is that bullets began as an innocuous typographical device or mark of punctuation and became a controversial genre of communication known variously as "bullet list," "bullet point," or, most broadly, "a PowerPoint." Bullets gained importance as they came not only to "mark" but also to "signify," that is, to carry meaning in addition to performing a function. One of the sources of power and tension in the history of bullets is the role of convention in both enabling and undermining effective communication. Each era in the history shows a strong correlation between the available technologies for the creation and presentation of information and the characteristic uses and meanings of bullets. This particular paper focuses on the first 40 years of that history, roughly 1950-1990.

Method: Sources for Constructing the History of Bullets

At the time we began the research reported here, the published history of bullets generally and of PowerPoint specifically was fragmented, contradictory, poorly documented, and largely anecdotal. All of these characteristics are reflected in the flurry of remembrance and reflection 
inspired by the $20^{\text {th }}$ "birthday" (as it was often called) of PowerPoint in 2007. ${ }^{\text {iii }}$ Many of these retrospective accounts took the form of or used as their sources recollections by individuals involved in the early development of PowerPoint and, implicitly or explicitly, either foreshadowed the success of PowerPoint or attempted to deflect criticism of it. These accounts have much to recommend them, including proximity to the events of interest, but by their nature lack objectivity and comprehensiveness. This paper begins the process of transforming that history into a more coherent and credible form.

Our method in constructing this history, therefore, has focused on four categories of documents that qualify as primary sources: (1) the history of the word "bullet" as documented in the Oxford English Dictionary (OED), (2) the proposals in which the product we know as PowerPoint was first described, (3) communication textbooks and handbooks, and (4) NASA reports in which bullets are used and Richard Feynman's critique of that use.

Category 1: The history of the word "bullet" as documented in the Oxford English Dictionary $(O E D)$. In addition to reporting the first known appearance of a particular word in print, the OED follows the evolution of the word's meaning. Each notable change is illustrated by a brief quote that shows not only where and when the word was used but the context of use. Taken together, these pieces of information make it possible to get not only a sense of changes in meaning but also of the factors driving change.

Category 2: The proposals in which the product we know as PowerPoint was first described. Microsoft released PowerPoint in 1987, but the concept for such a product was proposed by Robert Gaskins of Forethought Inc. in outline form in 1984 and in detail in 1986. Both proposals articulate the problems the software was designed to overcome and the positive vision that it sought to achieve. They also illustrate that, even from the beginning, PowerPoint was not just a product but rather a new genre of communication.

Category 3: Communication textbooks and handbooks. In some cases and with regard to some issues, the textbooks mirror common practice and acquaint readers with established conventions. In other cases, these books advocate innovative practices that are not widely used but have potential merit based on theory and experiment. Such is the case with alternative slide structures, such as found in texts by Reynolds, ${ }^{\mathrm{iv}}$ Duarte, ${ }^{\mathrm{v}}$ Atkinson, ${ }^{\mathrm{vi}}$ and Alley. ${ }^{\mathrm{vii}}$ These sources provide documentation of evolving practice through what they do (the extent to and ways in which they employ bullet lists) and what they say (the recommendations they make about the use of such lists and the rationale, if any, that they provide).

Category 4: NASA reports in which bullets are used and Richard Feynman's critique of that use. The Rogers Commission investigation into the Challenger Disaster drew attention to bullet lists as a conventional mode of communication within NASA, a convention that appears to have been well-established by the time the accident occurred. In his 1988 Physics Today paper "An Insider's Outside View of the Space Shuttle Challenger Disaster," Nobel Prize winning physicist Richard Feynman described his experience as a member of the Rogers Commission. His pointed critique of the use of bullet lists in NASA presentations and reports marks the beginning of public awareness of bullets as a flawed and potentially dangerous form of communication. 
The Early History of Bullets: The Typographical Era (1950- 1980)

The first documented use of the word "bullet" in print in 1950 makes it clear that the bullet was originally understood as a typographical device. ${ }^{\text {viii }}$ For the better part of the preceding 400 years (roughly 1550-1950), the word "bullet" signified a small round material object, and, more narrowly, the projectile of metal used as ammunition in firearms. Over time, the shape and behavior of the bullet as weapon were abstracted to the qualities of speed, sleekness, shininess, and streamlined conical shape, for example, as in "bullet train," which first appeared in print in 1966.

The first use in print of the term "bullet" as a typographical device (rather a weapon) suggests that bullets were initially associated with print advertisements. That first use occurred in 1950 in the New York News Type Book, a reference book produced in the Mechanical Department of the New York News that describes itself as "a permanent desk manual for the advertising, layout, and production man - and for the business man who wishes to put his own advertising copy into proper shape for publication" ( $\mathrm{p}$. iii). ${ }^{\text {ix }}$

The bulk of the book reproduces "the type faces and sizes that are available in the Composing Room of the New York News" (title page). It attempts to give people who are preparing advertising copy insight into the techniques and procedures used by lithographic composers as they sit at their machines. These insights are designed to help originators of copy understand how choices about typography affect the cost of actually printing an advertisement (as opposed, for example, to its effectiveness).

"Bullets" fall into the last section of the book called "Accessories." This category includes marks such as solid and open stars, boxes, solid diamonds, asterisks, checks, plus signs, equal signs, arrows, open and closed fists, ornamental brackets, braces, and panatelas (straight lines that are thinner on the ends than in the middle). All "accessories" are available in various sizes, in the case of bullets ranging from 8 to 24 points (p. 109). The book neither discusses the function of bullets in advertisements nor distinguishes them from any of the other items in the "accessories" category.

Figure 1, a newspaper advertisement published in 1950, illustrates typical use of bullets as an accessory. ${ }^{\mathrm{x}}$ Our initial review of advertisements from the 1950s suggests that bullets were not pervasively used in advertisements. When they were used, it appears their primary purpose was to add interest to white space.

If we use the evolving meaning of the term as charted in the OED as a guide, we see that the function of bullets is expanded by 1960, when the OED adds the definition of bullets as "small ornaments. . primarily useful as type-breakers, story-starters, and story-enders, in which instances they are usually referred to as dingbats, bullets, or spots." This citation suggests that the use of bullets has expanded from advertisements to longer documents. An OED citation from 1971,

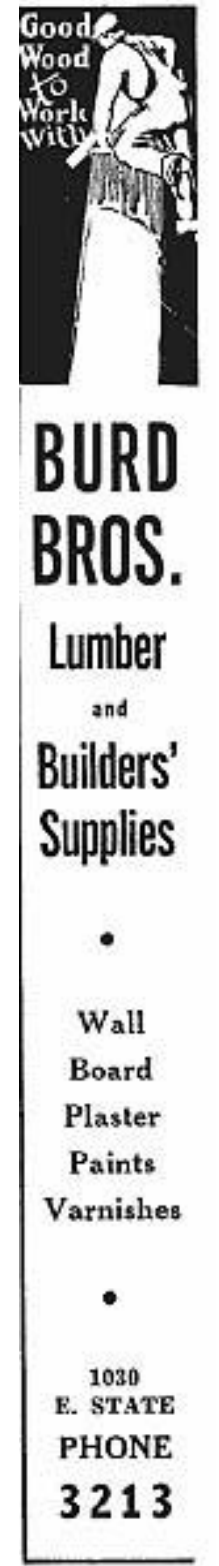

Figure 1. 
indicates that editors had begun "using various-sized dots or bullets at the beginning of a paragraph as a means of breaking up large gray masses of type." Throughout this period, the shape of the mark is less important than its size or characteristic position in the text. Bullets are understood as a device to attract the attention of readers and as a complement to white space in making text easier for readers to understand.

\section{A Confluence of Forces 1984-1986: The "Birth" of Presentation Software}

The proposals of Robert Gaskins (1984 and 1986), as described above, provide a rich account of the context in which and the confluence of factors that gave rise to PowerPoint. ${ }^{\text {xi }}$, xi The first of these, dated August 14, 1984, printed on a dot matrix printer, and titled "Sample Product Proposal: Presentation Graphics for Overhead Projection," is a two page document that begins as a hierarchical topic outline but also consists of two other levels of information: (1) assertions of fact marked by indentation and without initial punctuation and (2) lists of activities, functions, features, and products marked by a double-hyphen (dash).

The second document, dated July 15, 1986, is a set of 26 slides titled " ' Presenter' New Product Summary and Review." These slides expand the two-page document by summarizing the features of the new product, describing the needs the product meets and the opportunities it exploits, and providing recommendations for marketing and establishing strategic partnerships. Perhaps most importantly, as a set of slides produced on a personal computer and designed for overhead projection, it demonstrates the product in addition to describing it.

Among many other things, these documents illustrate that PowerPoint was a manifestation of both "technology push" and "market pull."xiii The "push" came from the individuals and organizations who sought to expand the market for PCs, software, and peripherals. The "pull" emerged as a desire, mostly on the part of those making presentations, for an alternative to 35 $\mathrm{mm}$ slides and the style of presentation that had coalesced around their conventional use.

Gaskins' proposals documented the growing number of presentations using visual aids and emphasized that many of the people making the presentations had the authority to sign purchase orders in the amounts required to create a complete "presentation environment," the hardware and software required to create and display presentation visuals. The case to potential users focused on two central goals: (1) saving time and money and (2) shifting power (i.e., control over the content of the presentation) away from graphics departments and toward content originators.

As reproduced in Figures 2 and 3 below, the slides from the 1986 presentation exhibit the features most strongly associated with PowerPoint today and discussed in the proposal itself:

- a standardized format including the company logo

- headlines followed by bulleted lists

- dominance of text over visual images

- merging of functions in which a single set of slides is designed to serve simultaneously as speaker's notes, slides the audience will see, and print documentation for later reference 


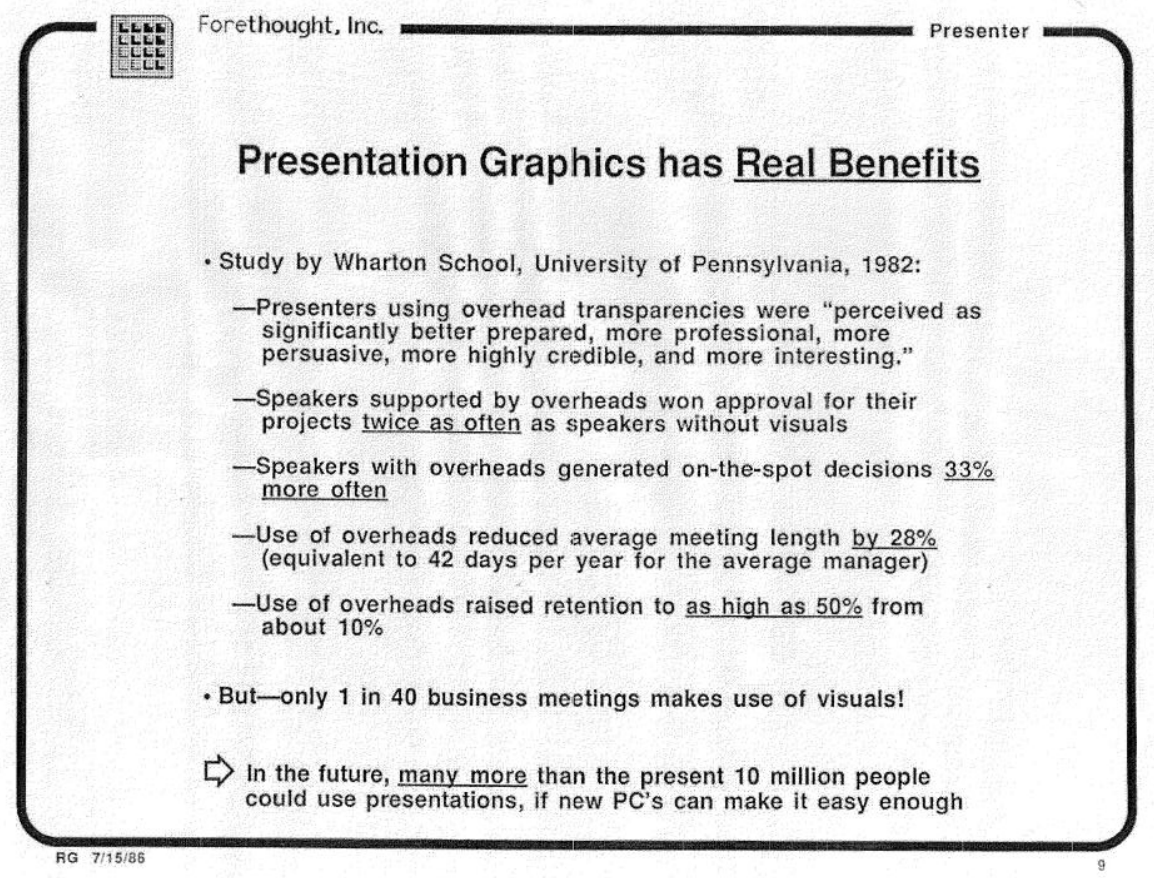

Figure 2. Sample Slide from Gaskins’ 1986 Presentation.

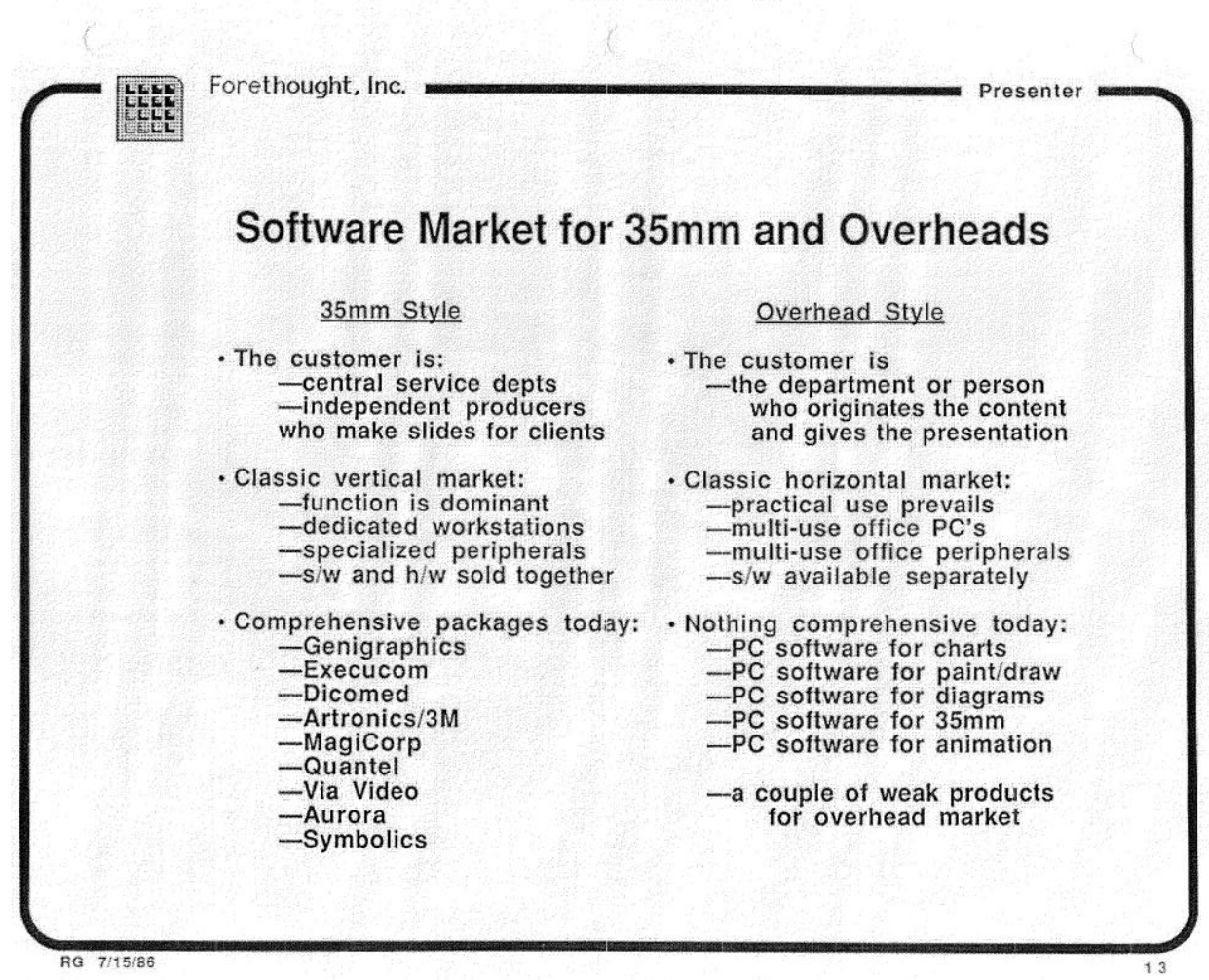

Figure 3. Gaskins' Comparison of the Software Markets for 35mm vs. Overheads. 
One of the most interesting slides is reproduced below as Figure 4. Like Figure 3, it makes it clear that "Presenter" was originally envisioned primarily as a way to create transparencies for overhead projection. But it takes the comparison further by indicating that "Presenter" would make it possible to replace the presentation style associated with an older technology $(35 \mathrm{~mm}$ slides) with a newer and more effective style associated with a newer but still established technology (overhead transparencies). The bulk of Gaskins' analysis centers on the weaknesses of $35 \mathrm{~mm}$ slides and the strength of overhead transparencies and projectors. The proposal (incorrectly) forecasts that the "Bulk of presentations will continue to be made with transparencies," though "Video Overheads" will eliminate the need for physical transparencies.

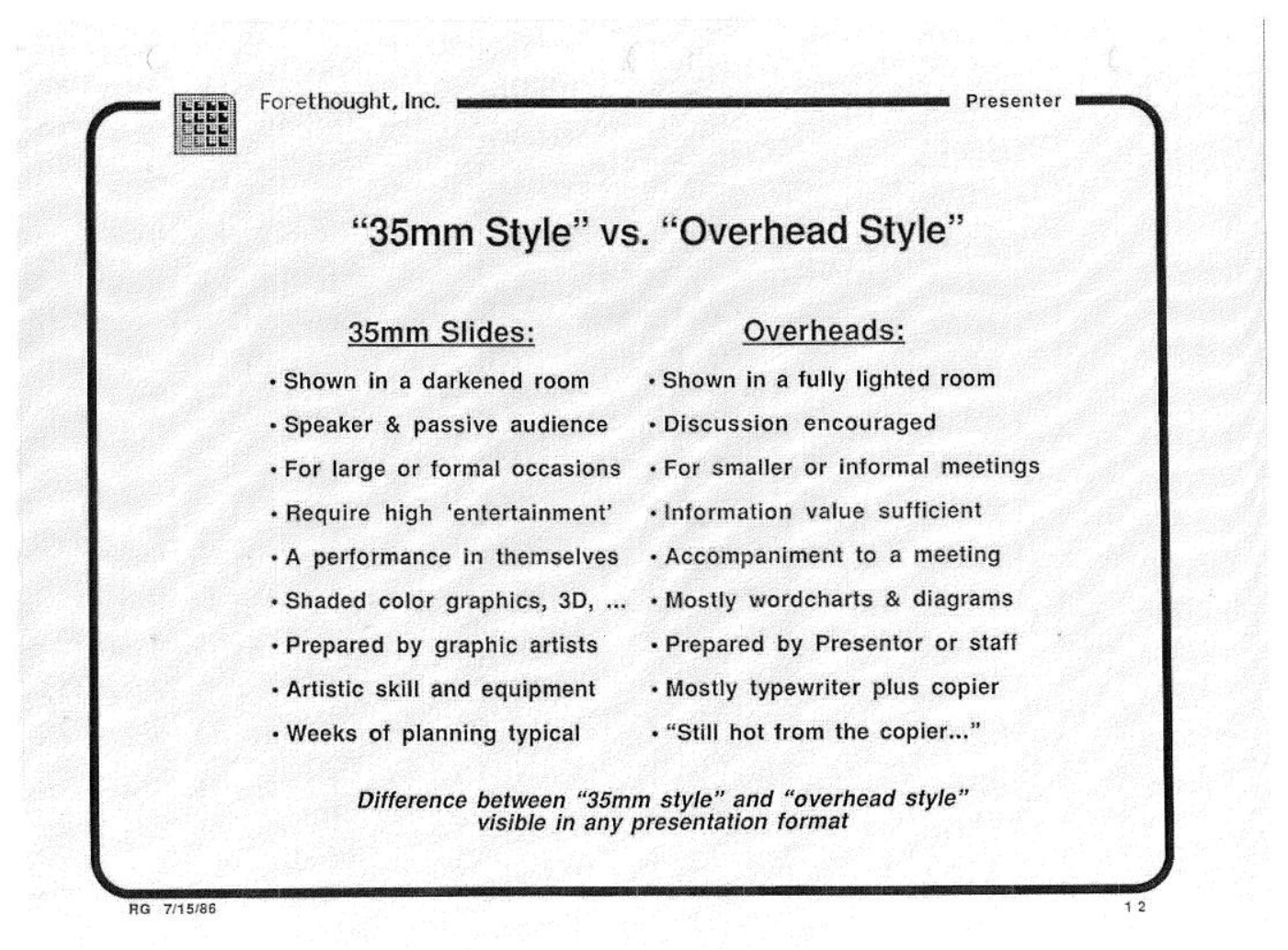

Figure 4. Gaskins' Comparison of “35 mm Style” vs. "Overhead Style”

Gaskins' presentation emphasizes some of the most important values associated with bullet lists in general and PowerPoint in particular: efficiency, multifunctionality, and advanced technology as the basis for improved practices and organizations.

1987 to the 1990s: Proliferation as the "Bullet Point" Becomes a Genre of Communication

As mentioned earlier, in the early 1980s, the definition of the "bullet" as a typographic symbol or mark of punctuation persisted, but the "bullet" also began to acquire a strong association or identification with lists. The "bullet list" gives way to the "bullet point," which the OED defines as "a concise statement or summary marked with a typographical bullet, esp. one of several in a 
list (also in extended use); (also) a typographical bullet." The examples incorporated into the OED during this period illustrate how the new meaning develops. For example, a 1983 book review in Datamation notes "Each chapter concludes with a bullet-point list of 'things to think about' or 'things to remember', which is particularly helpful if it's been a few days between chapters," which suggests that bullet lists serve as a summary of previously presented material. In 1999, an article in a local newspaper reports "He told the senior citizens. . that he was about to give them the 'bullet points' of his program," a usage that implies a stand-alone synthesis or distillation rather than summary. In 2004, a news magazine describes a publication called Taking Action as "studded with bullet points saying what the British government is going to do next." This last citation associates bullets with an active stance and approach.

The 1980s witnessed a dramatic rise in the use of bullets in both technical presentations and in technical writing. This increase correlates with expanded use of personal computers and the ability to project electronic as opposed to hard copy images. In other words, electronic communication gradually became the norm. Without question, the biggest catalyst for the increase came from the incorporation of bullet lists into the defaults of Microsoft PowerPoint, which was introduced in 1987. With the meteoric rise in the use of this program came an equally dramatic rise in the use of bullets. It is important to note, however, that bullets pre-existed PowerPoint. The next section of the paper tracks the history of bullets as it is revealed in technical communication textbooks.

Tracing Discussion and Use of Bullets in Technical Communication Textbooks. Technical communication textbooks provide another interesting perspective on the styles of writing and presentations that one finds in industry. On certain issues, these books are ahead of common practice and encourage the technical community to embrace new stylistic choices supported by theory and experimental data.

The earliest discussion of bullets that we found in a technical writing textbook appears in Edmond H. Weiss's text The Writing System for Engineers and Scientists, ${ }^{\text {xiv }}$ which was published in 1982. Much of the discussion about bullets centered on the challenge of persuading typists to create bullets. At the time, creating bullets was a two-step process: first typing lowercase $o$ 's and then "filling in the lowercase $o$ 's with a pen." "xv Weiss does include a sentence indicating that bullets were becoming popular: "Nowadays, though, lists are so popular (especially lists with 'bullets')." xvi

Most technical writing textbooks during the 1980s and 1990s simply reflected the trend of bullets found in industry and government writing. In The Handbook of Technical Writing, ${ }^{x v i i}$ a discussion about bullets did not appear until the 3rd edition, which was published in 1987 and was concurrent with the emergence of PowerPoint. Brusaw et al. simply wrote that bulleted lists should be used "[if] you do not wish to indicate rank or sequence."xviii Brusaw et al. also commented that a bullet is created with "a small $o$ that is filled with ink." Interestingly, the use of bulleted lists by Brusaw et al. increased with subsequent editions. For instance, for the entry on "oral presentations" in the $3^{\text {rd }}$ edition, the authors incorporated one bulleted list in the 10 pages of discussion. ${ }^{\text {ix }}$ However, in the $5^{\text {th }}$ edition, which appeared in 1997, the same entry had six bulleted lists. ${ }^{\mathrm{xx}}$

Similarly, Houp and Pearsall did not say much about bullets in their sixth edition of Reporting Technical Information, which was published in 1988 and which used bullets judiciously. ${ }^{\mathrm{xxi}}$ However, in the seventh edition, which came out in 1992, ${ }^{\text {xii }}$ bulleted lists were used often, 
including the inside front cover. In the preface, Pearsall provided a hint as to the origin of these lists in this text by explicitly mentioning the "new and fresh design" created by the Macmillan team. Between the lines, one can infer that it was not the technical communication authors, but the publisher that was pushing the device, perhaps driven by competition with other publishing houses.

In her third edition of Technical Communication, which she published in 1994, ${ }^{\text {xiii }}$ Rebecca Burnett wrote more about bullets than either Brusaw et al. or Houp and Pearsall. Burnett was careful to distinguish between numbered lists and bulleted lists, citing that numbered lists are more effective when communicating sequence, priority, or the total count of items. She went on to say that a bulleted list is "preferable" when all the items are equivalent in importance. As a sign of the times, Burnett discussed how to create bullets when using a typewriter, as opposed to a word processing program. Just as Weiss had discussed, Burnett's advice was to type the letter $o$ and then fill it in.

Perhaps the most in-depth discussion, though, about bullets appeared in Lannon's $6^{\text {th }}$ edition, ${ }^{\text {xxiv }}$ which came out in 1994. Lannon began the discussion with the following sweeping assertion: "Readers prefer information in list form rather than in continuous prose paragraphs." This statement Lannon backed up with a reference to James Hartley's book on design, Designing Instructional Texts. ${ }^{\mathrm{xxv}}$ In the rest of this section, Lannon did mention a number of qualifications to the statement. Certainly, lists are not always preferred in writing, and Lannon did point out toward the end of the section that "a document with too many lists appears busy, disconnected, and splintered," anchoring this statement with a reference to a 1981 government report by Felker et al.

Felker et al. examined a number of topics concerning style and typography in writing by presenting advice on each topic, giving several examples to back up the advice, then presenting qualifications to the advice, and concluding the advice with a discussion of supporting research. ${ }^{\text {xvi }}$ In the report, Felker et al. grouped bullets with other typographical cues such as dashes or checkmarks. In the qualifications section of this discussion, Felker et al. stated the following: "If you use too many lists with bullets... in consecutive paragraphs, your document will look cluttered and start sounding choppy."xxvii They also pointed out that "[i]f you have only two or three parallel items in an occasional sentence, there is usually no need to break them into a list., $x x v i i i$

Unfortunately, the qualifications that stood out so much in Felker et al. were buried or nonexistent in technical writing books. In effect, the many readers of those technical writing texts were encouraged to use bulleted lists, but not instructed on what overuse would be or even that they should avoid overuse. These texts reflect new meanings associated with bullet lists: respect for audience's time and attention, adaptation to the changing desires of readers, and respect for convention.

So, once word processors removed the typing challenge of creating a bullet and the combination of personal computers and LED projection realized Gaskins' original vision of "virtual overheads," it was not surprising that the widespread use of bulleted lists in reports and other documents soon followed. Moreover, for users of Microsoft PowerPoint, the program's defaults made it such that not having bullets was more work than having bullets. For that reason, the finding that bullets exist on more than two-thirds of the slides in engineering presentations, including presentations at engineering education conferences, ${ }^{\text {xix }}$ is not at all surprising. 
Tracing of Bullet Use in NASA Reports. As we mentioned in the earlier discussion of sources for constructing the history of bullets, the investigation following the Challenger disaster drew attention to bullet lists as a conventional and flawed mode of communication within NASA, and organization whose reports provide an interesting measure of the evolution of bullets. An examination of a sampling NASA reports during the beginning of the 1980s decade reveals that the style at that time was for numbered lists rather than bulleted lists (see Figure 5 for an example). By the mid-1980s, as Feynman noted, bullets were quite commonly used during the in NASA reports, especially for the conclusion and recommendation sections. Thus, it appears that bullet lists became popular in NASA between 1980 and 1985 and evolved from numbered lists.

\subsection{CONCLUSIONS AMD RECONENDATIONS}

The following conclusions are supported by the develorments and analyses described herein:

1. A useful capability has been developed for conduct ing both pilotes and non-piloted simulations of the terminal operations of VATQ airplanes. This simulation capability can be, but is not restricted to being. applied at conceptual design phases where relat'vely few configuration - specific data are available. It will highlight handling qualities characteristics which are indigenous to the various designs.

2. The derodymamics math model is deterministic, functions with DATCOH type data, and can adequately represent the low speed high angle of attack, large sideslip aerodynamic characteristics of VATO airplanes.

3. The Vought Sf-121 airplane, as modeled herein, has adequate control power for meeting the trim and maneuvering requirements of the MIL-F-83300 and AGARD 577 flying qualities specifications with some residual for gust regulation.

4. The baseline FCS developed for the SF-121 provides an adequate starting point for piloted simulation studies.

5. The most distinguishing flying qualities characteristic of the SF-121 airplane (ar,d similarly thrust deflected controlled vaTO airplanes) is a strong non-miniaum phase control characteristic (i.e. initial acceleration in wrong direction) which will become apparent when the pilot attempts tight horizontal plane position control in hover.

Figure 5. Typical conclusion and recommendation section for a 1980 NASA report. ${ }^{\mathrm{xx}}$ In the style of this time, numbered lists were used rather than bullet lists.

An interesting note, though, is that some sub-lists in the 1980 reports did have an open circle bullet, as shown in Figure 6. It could be that this open circle was a precursor to the bullet at NASA. Moreover, the preference of numbered lists rather than bulleted lists might have been because creating a true bullet was a two-step process at that time, as discussed earlier. 
provide continuous attitude references for attitude control loops throughout the operating range of VAT $\alpha$ airplanes. If the approach has merit, incorporate the appropriate relations into the math model.

2. Determine and correct, if necessary, the mechanism for the small oscillation in roll rate which appears to occur under conditions of simultaneous high angle of attack rates, large sideslips, and relatively high steady state roll rates (Section 3.8.10).

3. Piloted simulation studies should consider at $l \in$ ast the following issues regarding terminal nper-tions of VAT $\alpha$ airplanes:

- Mon minimum phase control characteristics and their impact on pilot comfort, workload, and ability to effect precise position control in hover and on the need for additional moment controls (e.g. independent pitch and yaw RCS). cockpit and/or pilot rotation during transition. First consider its necessity. If required, then consider whether switching of cockpit controller roles and pilot/cockpit angle control should be automatic or manual functions.

- Transition control system considerations - control system type (rate command, rate command/attitude hold, attitude comanan, etc), automatic or manual mode switching, mode blending, annoyance level of uncommanded motions during mode switching, corkit controller authorities and sensitivities, pilot input command shaping requirements, system bandwidths, gust regulation capabilitie..

Figure 6. Use of open-circle bullet in a conclusion and recommendation section from a 1980 NASA report. ${ }^{\text {xxi }}$

These communication practices apparently went unnoticed outside of NASA and uncritiqued within NASA until Richard Feynman published an article entitled "An Outsider's View of the Challenger Inquiry" in Physics Today in February of 1988. Feynman portrays himself as a skeptic and deliberately positions himself outside of - and to some extent in opposition tobureaucratic organizations and procedures. Most importantly for our purposes here, Feynman focuses on the recommendation page, shown in Figure 7, from a 1986 NASA report that preceded the Challenger disaster by more than five months (and the advent of PowerPoint by one year).

Feynman highlights the contradiction between the first and sixth bullet (those underlined in the figure). Specifically, the first bullet indicated that the problem with the secondary seal was "critical," while the sixth bullet concluded that it was "safe to continue flying." 


\section{Recommendations}

- The lack of a good secondary seal in the field joint is most critical and ways to reduce joint rotation should be incorporated as soon as possible to reduce criticality

- The flow conditions in the joint areas during ignition and motor operation need to be established through cold flow modeling to eliminate D-ring erosion

- QM-5 static test should be used to qualify a second source of the only flight certified joint filler material (asbestos-filled vacuum putty) to protect the flight program schedule

- VLS-1 should use the only flight certified joint filler material (Randolph asbestos-filled vacuum putty) in all joints

- Additional hot and cold subscale tests need to be conducted to improve analytical modeling of $\mathrm{O}$-ring erosion problem and for establishing margins of safety for eroded O-rings

- Analysis of existing data indicates that it is safe to continue flying existing design as long as all joints are leak checked with a 200 psig stabilization pressure, are free of contamination in the seal areas aad meet $\mathrm{O}$-ring squeeze requirements

- Efforts needs to continue at an accelerated pace to eliminate SRM seal erosion

Figure 7. Bullet list from a 1985 NASA report. ${ }^{\text {xxxii }}$

Commenting upon this list and the many others like it, Feynman asserts, "This is how all information is communicated by NASA - by writing down everything behind little black circles, called 'bullets." "xxxiii In his book What Do You Care What Other People Think? Feynman expresses an irritation with bullets that borders on disdain: "Then we learned about "bullets" - little black circles in front of phrases that were supposed to summarize things. There was one after another of these little goddamn bullets in our briefing books and on the slides."xxxiv

For Feynman, this style of communication supports but also obscures the development of a dangerous attitude: "If the seals leaked a little and the flight wasn't successful, it meant that the seal situation wasn't serious. Therefore, the seals could leak and it would be all right - it was no worse than the time before." He likens this attitude to playing Russian roulette, but in the case of the Challenger, the individual making the decision to take the risk would not be the one most at risk. His analysis exemplifies what might be called "the ethical turn" in critique of PowerPoint: bullet lists become emblematic of a flawed, and indeed ethically suspect, approach to interpreting evidence and communicating the rationale for decisions. ${ }^{\mathrm{xxv}}$ This recognition of the ethical dimensions of a particular style of communicating underlies much of the vociferous critique of PowerPoint that appeared in the 1990s.

Conclusion 
Feynman's analysis highlights the ways in which the history of bullets in technical communication serves as a case study in Petroski's assertion that clear technical communication is the foundation for the responsible, ethical practice of engineering. What began as an attempt to enhance clarity, improve efficiency, and empower individual presenters evolved into a set of practices with outcomes that are often perceived as the antitheses of those original goals. The history of bullet lists provides us a critical perspective from which we can optimize the potential of bullet lists, presentation software, and the practices associated with them. Framing that optimization within the larger goal of shaping communication practices so that they support the ethical goals of engineering should help encourage individuals and institutions to make the investments that will be required.

\section{Bibliography}

i Petroski, Henry. (1985). To Engineer Is Human: The Role of Failure in Successful Design, p. 52

ii Joanna Garner, Michael Alley, Allen Gaudelli, and Sarah Zappe. 2009. Common Use of PowerPoint versus Assertion-Evidence Slide Structure: a Cognitive Psychology Perspective. Technical Communication, 56 (4), $331-345$.

iii See, for example, "The Problem with PowerPoint," BBC News Magazine (2009) news.bbc.co.k./go/pr/ /2/hi/uk_news/magazine/8207849 and Gomes below.

${ }^{i v}$ Reynolds, Garr (2008). Presentation Zen. Berkeley, CA: New Riders.

${ }^{\mathrm{v}}$ Duarte, Nancy (2008). Slide:ology. Sebastopol, CA: O'Reilly Media.

${ }^{v i}$ Atkinson, Cliff (2005). Beyond Bullet Points: Using Microsoft PowerPoint to Create Presentations That Inform, Motivate, and Inspire. Redmond, WA: Microsoft Press.

${ }^{\text {vii }}$ Alley, Michael (2003). The Craft of Scientific Presentations. New York: Springer-Verlag. viii “Bullet," Oxford English Dictionary Online. (1988) http:// dictionary.oed.com/ Accessed September 9, 2010. The meaning associated with "bullet train" appeared in the Additions Series to the OED (1993). The meaning associated with the bullet as typographical symbol was proposed as part of Draft Additions in June, 2006.

ix New York News (1950) The News Type Book. New York: News Syndicate Co., Inc.

x This advertisement appeared in the Times Herald in 1950.

xi Gaskins, Robert (1984). "Original Powerpoint Proposal."

http:/ / www.robertgaskins.com/pages/gaskins-original-powerpoint-proposal-14-aug-1984.pdf

xii Gaskins, Robert (1986). "Presenter Powerpoint Slides."

http://www.robertgaskins.com/pages/gaskins-presenter-(powerpoint)-slides-july-1986.pdf

xiii Volker, Mike (2010). “Business Basics For Engineers: Technology Push vs. Market Pull."

http:/ /www.sfu.ca/ mvolker/biz/pushpull.htm

${ }^{x i v}$ Weiss, Edmund H. (2002). The Writing System for Engineers and Scientists. Englewood Cliffs, NJ: Prentice-Hall.

${ }^{\mathrm{xv}}$ Ibid, p. 228.

${ }^{\text {xvi }}$ Ibid, p. 257.

${ }^{\text {xvii }}$ Brusaw, Charles T., Gerald J. Alred, and Walter E. Oliu (1987). The Handbook of Technical Writing, $3^{\text {rd }}$ ed. New York: St. Martin's Press.

xviii Ibid, p. 386.

${ }^{\text {xix }}$ Ibid, pp. 455-465. 
${ }^{x x}$ Brusaw, Charles T., Gerald J. Alred, and Walter E. Oliu (1997). The Handbook of Technical Writing, $5^{\text {th }}$ ed. New York: St. Martin's Press, pp. 400-410

${ }^{x x i}$ Houp, Kennety and Thomas E. Pearsall (1988). Reporting Technical Information, $6^{\text {th }}$ ed. New York: MacMillan.

${ }^{x x i i}$ Kenneth Houp and Thomas E. Pearsall (1992). Reporting Technical Information, $7^{\text {th }}$ ed. New York: MacMillan, p. ix.

${ }^{x x i i i}$ Rebecca Burnett (1994). Technical Communication, $3^{\text {rd }}$ ed. Belmont, CA: Wadsworth Publishing Co., p. 233.

${ }^{x x i v}$ John M. Lannon (1994). Technical Writing, $6^{\text {th }}$ ed. New York: Harper Collins College Publishers, p. 355.

${ }^{\mathrm{xxv}}$ James Hartley (1985). Designing Instructional Text, $2^{\text {nd }}$ ed. London: Kogan Page, p. 51.

${ }^{x x v i}$ Daniel Felker, Frances Pickering, Veda R. Charrow, V. Melissa Holland \& Janice C. Redish (1985). Guidelines for Document Designers. Washington: American Institutes for Research.

xxvii Ibid, p. 55.

xxviii Ibid, p. 55

xxix Joanna Garner, Michael Alley, Allen Gaudelli, and Sarah Zappe. 2009. Common Use of PowerPoint versus Assertion-Evidence Slide Structure: a Cognitive Psychology Perspective. Technical Communication, 56 (4), 331-345.

${ }^{\mathrm{xxx}}$ Robert Fortenbaugh (1980, December). A Mathematical Model for Vertical Attitude Takeoff and Landing (VATOL) Aircraft Simulation. NAS2-10294 (Dallas, TX: Vought Corporation for NASA Ames Research Center), p. 189.

${ }^{\mathrm{xxxi}}$ Robert Fortenbaugh (1980, December). A Mathematical Model for Vertical Attitude Takeoff and Landing (VATOL) Aircraft Simulation. NAS2-10294 (Dallas, TX: Vought Corporation for NASA Ames Research Center), p. 190.

${ }^{\mathrm{xxxii}}$ Report of the Presidential Commission on the Space Shuttle Challenger Accident, vol. 1 (Washington, DC: White House Press, 1986), p. 139.

xxxiii Richard Feynman (1988, February). An insider's outside view of the Space Shuttle Challenger disaster. Physics Today, pp. 26-37.

${ }^{\text {xxxiv }}$ Richard P. Feynman (1988). What Do You Care What Other People Think? New York: Norton, pp. 126-127 xxxv Edward R. Tufte extended and intensified this critique in the wake of the Columbia disaster, most notably in an essay called The Cognitive Style of PowerPoint (2003). 